\title{
A 14-day regimen of high-dose inhaled corticosteroids was more effective than placebo for persistent nocturnal cough
}

Davies MJ, Fuller P,Picciotto A, et al.Persistent nocturnal cough: randomised controlled trial of high dose inhaled corticosteroid. Arch Dis Child 1999 Jul;81:38-44.

QUESTION: In children with isolated nocturnal cough, how effective is a short course of high-dose inhaled corticosteroids?

\section{Design}

16-day randomised (allocation concealed*), blinded (clinicians and patients), ${ }^{*}$ placebo-controlled trial.

\section{Setting}

East London, UK.

\section{Patients}

50 children who were between 1 and 10 years of age (58\% between 1 and 4 y, 60\% girls) and had persistent nocturnal cough (coughing at night for $>3 \mathrm{wks}$ ). Exclusion criteria were upper respiratory tract infection, history of wheeze or fever, or identifiable cause for cough (whooping cough, persistent nasal discharge, or large tonsils). 44 children (88\%) had outcomes measured on nights 3 and 4, and 47 (94\%) had outcomes measured on nights 15 and 16 .

\section{Intervention}

Children were allocated to inhaled corticosteroids (fluticasone propionate) $(n=26)$ or placebo $(n=24)$ delivered by metered-dose inhaler. Children received a dose of $1 \mathrm{mg}$ twice daily for 3 days and were observed for 2 nights; they then received $500 \mu \mathrm{g}$ twice daily for 11 more days and were observed for 2 more nights.

\section{Main outcome measures}

Change in total coughs from baseline and proportion of children with $\geq 75 \%$ improvement from baseline on nights $3,4,15$, and 16 measured by using a videorecording system.

\section{Main results}

Children in both groups had fewer coughs than at baseline on nights $3,4,15$, and 16 . Children who received inhaled corticosteroids had a greater median decrease from baseline in coughs than placebo recipients on nights 15 and 16 (93\% [from 92 to 8 median coughs] $v$ $68 \%$ [from 71 to 36 median coughs], $\mathrm{p}=0.02$ ) but not on nights 3 and 4 (78\% [from 92 to 23 median coughs] $v 43 \%$ [from 71 to 66 median coughs], $\mathrm{p}=0.38$ ). The proportion of patients with $\mathrm{a} \geq 75 \%$ improvement was also greater in the inhaled-corticosteroids group than the placebo group on nights 15 and $16(\mathrm{p}=0.03)$ but not on nights 3 and $4(\mathrm{p}=0.76)$ (table). Improvement over baseline coughing was not related to positive skinprick test result, IgE level, or family history of atopy.

\section{Conclusions}

In children with persistent nocturnal cough, substantial resolution occurred with time. A course of high-dose inhaled corticosteroids produced modest additional benefit after 14 days but not after 3 days.

*See glossary.

\section{COMMENTARY}

Isolated troublesome cough, particularly at night, is a common childhood symptom that in recent years has increasingly been labelled and treated as asthma. More recent studies have suggested that isolated cough is distinct from asthma. ${ }^{1}$

Cough is unreliably reported; therefore, the development of practical methods for objective cough counting has been an important advance. 2 recent studies have used cough counting to examine the effects of asthma treatment in children with isolated cough. Chang and colleagues studied children 6-10 years of age with recurrent cough (two 2-wk episodes in $12 \mathrm{mo}$ ) and found that neither salbutamol nor beclomethasone was superior to placebo in reducing cough. $^{2}$

Davies and colleagues studied children 1-10 years of age with isolated persistent nocturnal cough (night coughing $>3$ wks). The children were referred from the community. The investigators excluded common causes of cough, and nocturnal cough was confirmed by cough counting on video before randomisation to placebo or high-dose inhaled fluticasone for 2 weeks. In both groups, cough improved substantially during the 2-week follow-up. However, a modest but significantly greater reduction in cough occurred after 2 weeks in patients receiving high-dose inhaled steroids.

Where does this leave the paediatrician? We should exclude other causes of cough; know that time will bring substantial resolution to most; and if coughing persists, recognise that a 2-week course of high-dose inhaled fluticasone may hasten resolution. Prolonged or repeated courses of high-dose steroids for isolated cough are not justified.

$$
\text { James Y Paton, MD, MBChB }
$$
University of Glasgow Glasgow, UK

1 Chang AB. Isolated cough: probably not asthma. Arch Dis Child 1999;80:211-3.

2 Chang AB, Phelan PD, Carlin JB, Sawyer SM, Robertson CF. A randomised, placebo controlled trial of inhaled salbutamol and beclomethasone for recurrent cough. Arch Dis Child 1998;79:6-11.
Inhaled corticosteroids v placebo for persistent nocturnal cough $\dagger$

\begin{tabular}{lllll}
$\begin{array}{l}75 \% \text { improvement } \\
\text { over baseline }\end{array}$ & $\begin{array}{l}\text { Inhaled } \\
\text { corticosteroids }\end{array}$ & Placebo & RBI (95\% Cl) & NNT (CI) \\
Nights 3 and 4 & $55 \%$ & $45 \%$ & $20 \%(-34$ to 122$)$ & Not significant \\
\hline Nights 15 and 16 & $71 \%$ & $35 \%$ & $104 \%(15$ to 292$)$ & 3 (2 to 14) \\
\hline tAbbreviations defined in glossary; RBI, NNT, and Cl calculated from data in article.
\end{tabular}

Source of funding:

Glaxo Wellcome.

For correspondence: $\operatorname{Dr} S$ A McKenzie, Queen Elizabeth Children's Services, Royal London Hospital, Whitechapel London E1 1BB, UK 